\title{
Teaching Counseling Skills in Audiology Graduate Programs: Clinical Supervisors' Perceptions and Practices
}

DOI: $10.3766 /$ jaaa. 17078

\author{
Karen Muñoz ${ }^{*} \dagger$ \\ Trent Landon $\ddagger$ \\ Kim Corbin-Lewis*
}

\begin{abstract}
Background: Counseling is a critical component within audiological service delivery. Partnering with patients to support them in learning to effectively cope with their hearing challenges is a key component in achieving desired outcomes. Even though there is agreement on the foundational role counseling plays in audiology service delivery, counseling instruction varies among audiology training programs.
\end{abstract}

Purpose: The purpose of this study was to investigate the perspectives and practices of supervisors in audiology graduate training programs related to mentoring students in the acquisition of counseling skills.

Research Design: A cross-sectional design was used; participants completed a self-report survey.

Study Sample: The survey was sent to 323 clinical supervisors in AuD graduate programs in the United States.

Data Collection and Analysis: Completed surveys were received from 205 supervisors. Responses were analyzed using descriptive statistics to identify practice trends.

Results: Participants reported their perceptions about importance of teaching counseling skills to audiology students, their confidence in teaching skills, their self-efficacy for supporting student learning, how they provide feedback to students, and challenges they encounter. Most participants reported their program requires a counseling course $(88 \% ; n=176)$. Most of the participants reported confidence in teaching counseling skills; however, fewer reported being very or extremely confident in teaching students how to talk with clients about their emotions $(53 \% ; n=109)$ and explaining the rationale behind specific counseling strategies $(47 \% ; n=97)$. Participants with more years of supervisory experience had statistically significantly higher self-ratings for teaching confidence and self-efficacy for supporting student learning in counseling than those with fewer years of experience.

Conclusions: Audiology supervisors in AuD programs believe counseling is important to teach to students; however, they report variability in use of methods for providing feedback, evaluating student performance, and in their self-efficacy for supporting student learning. Future audiologists would benefit from a more systematic approach within graduate training for teaching counseling skills.

Key Words: audiology, counseling, supervision

Abbreviations: $\mathrm{ASHA}=$ American Speech-Language-Hearing Association

*Department of Communicative Disorders and Deaf Education, Utah State University, Logan, UT; †National Center for Hearing Assessment and Management, Utah State University, Logan, UT; †Department of Special Education and Rehabilitation, Utah State University, Logan, UT

Corresponding author: Karen Muñoz, Utah State University, 2620 Old Main Hill, Logan, UT 84322; Email: Karen.munoz@usu.edu

The work reported in this article was funded by the American Academy of Audiology/American Academy of Audiology Foundation Research Grants Program. The opinions expressed in this article are those of the authors and do not necessarily reflect those of the organization. 


\section{INTRODUCTION}

$\mathrm{C}$ ounseling is a critical component within the provision of audiological services to help patients achieve their goals and an improved quality of life. The purpose of counseling in audiology is to assess and address patient concerns and challenges that interfere with the intervention process. Counseling skills are needed to have intentional conversations that effectively support acceptance of diagnoses and guide treatment adherence. Counseling is included within the professional scope of practice (AAA, 2004; ASHA, 2004), described in Preferred Practice Patterns for the Profession of Audiology (ASHA, 2006), and included in professional practice guidelines (ASHA, 2008; AAA, 2013). Counseling can influence patient outcomes through individualized patient education and support (Shames, 2006; Luterman, 2008; Flasher and Fogle, 2012; Clark and English, 2014), and AuD training programs have an essential role in teaching foundational knowledge, skills, and attitudes for effective implementation of counseling in clinical practice.

A paradigm shift has been occurring in how health professionals approach healthcare conversations, moving from a biomedical to a biopsychosocial model (Heritage and Maynard, 2006; Levinson et al, 2010), often referred to as person- or family-centered care. This shift values the role of the patient in the encounter, striving to achieve a more balanced conversation between the practitioner and the recipient of services. Patient-centered interactions contain characteristics such as mutual trust, respect for patients' perspectives, assessment of and responsiveness to patients' needs, shared-decision making (e.g., agenda setting and action planning), and emotional support (Robinson et al, 2008). Professional-patient interactions within the context of patient-centered care improves treatment adherence (Robinson et al, 2008; Zolnierek and DiMatteo, 2009). Partnering with patients to support them in learning to effectively cope with their hearing challenges is a key component in achieving desired outcomes and can be facilitated through the application of appropriate counseling skills.

Even though there is agreement on the foundational role counseling plays in audiology service delivery, there is a lack of clarity in professional practice guidelines, leaving expectations for graduate training vague. Counseling competencies, like other skills audiologists learn, require intentional instruction for knowledge and skill acquisition to occur. Similar to student learning for other evidence-based audiology services, bridging of counseling knowledge is needed between coursework and clinical experiences. Counseling training in healthcare has been shown to increase the use of counseling strategies and increase confidence in counseling and communication skills (Delvaux et al, 2004;
Heaven et al, 2006; Ammentorp et al, 2007). If training is not provided, audiologists may miss opportunities to address client challenges, avoid addressing client emotions, and inadequately support needed behavior change to improve clients' intervention outcomes and quality of life.

Recent research has explored audiologist-patient interactions and counseling gaps have been observed (Ekberg et al, 2014; Grenness et al, 2015; Muñoz et al, 2017). This evidence is important to consider as it relates to counseling training in audiology graduate programs and represent areas where there is an opportunity for improvement. Studies that used audio recordings to better understand audiologist-patient encounters have found audiologists addressing technical issues at the expense of attending to clients' emotional concerns (Ekberg et al, 2014; Muñoz et al, 2017), directing the process rather than involving patients (Grenness et al, 2015), and verbally dominating encounters (Grenness et al, 2015; Muñoz et al, 2017). Patients have also reported that the information they received was either vague or too complex (Ross, 2004; Nair and Cienkowski, 2010; Watermeyer et al, 2012), and this may hinder their understanding and ability to use the information in a meaningful way. Individualizing information sharing and checking for understanding are critical aspects of patient education.

\section{Counseling Instruction}

Counseling-specific coursework provides audiology students with foundational knowledge to approach counseling with intention when engaging with clients. Counseling instruction; however, varies among AuD programs (Whicker et al, 2017), and practicing pediatric audiologists have reported wanting more training in counseling (Meibos et al, 2016). Only 15\% of pediatric audiologists reported receiving supervision related to counseling during graduate training. Supervision needs to include conversations about students' communication behavior with patients, and a strong supervisory relationship is needed to effectively engage students in such discussions. Supervisor characteristics have been shown to positively or negatively impact the supervisory working relationship, influencing the effectiveness of instruction and support for student learning (Ladany et al, 2013). Supervisors can improve learning outcomes and strengthen the supervisory relationship by diffusing the inherent power imbalance within clinical supervision (Schultz et al, 2002), a factor that can be further influenced by differences of gender and/or racial/ethnic backgrounds between the supervisor and supervisee. As an example, supervisors can initiate a simple discussion of these factors and their potential impact on the supervisory relationship with their supervisee. By doing so, the supervisor can positively influence the development 
of the supervisory relationship and trainee willingness to disclose critical factors for student learning (Walker et al, 2007; Ancis and Ladany, 2010).

The variability that exists in counseling instruction among AuD programs can influence how confident students feel in their ability to counsel patients, and ultimately, may negatively influence patient outcomes. Therefore, the purpose of this study was to investigate perspectives and practices of supervisors in audiology graduate training programs related to mentoring students in the acquisition of counseling skills.

\section{METHODS}

$\mathrm{T}$ his study used a self-report survey to explore supervisors' perspectives and practices. Institutional review board approval was obtained at Utah State University before the collection of data.

\section{Participants and Procedures}

Audiology clinical supervisors working in accredited graduate training programs in the United States, with current responsibility for providing student supervision in clinical practicum, were invited to participate. Accredited $\mathrm{AuD}$ clinical doctoral programs and their mailing addresses were identified using EdFind (http://www.asha. org/EdFind/), a database maintained by American Speech-Language-Hearing Association (ASHA) to provide information about the accredited academic programs in Communication Sciences and Disorders, based on annual surveys completed by the programs.

Program directors were contacted to verify audiology supervisors and the mailing address for each program. Clinical supervisors $(\mathrm{N}=323)$ in 73 programs were sent a survey packet that included a flyer to briefly describe the study, an institutional review board letter of information, the survey, a $\$ 5$ cash incentive to complete the survey, and a postage paid return envelope. The flyer included a link to enable the supervisors to complete the survey online, if preferred. Completed surveys were received from 205 clinical supervisors; a $63 \%$ response rate (see Table 1 for participant demographics).

\section{Instrument}

The survey instrument was developed by the authors. Before distributing the survey, two $\mathrm{PhD}$ students with supervisory experience completed the survey and provided feedback for face validity. Modifications were made before distribution of the survey, including rewording questions to improve clarity and removing redundant questions.

The survey included five sections (see Appendix): (a) demographic information (eight items); (b) items of importance to teach students (ten items) and related to
Table 1. Participant Demographic Information

\begin{tabular}{|c|c|c|}
\hline$N=205$ & M (SD) & Percent $(n)$ \\
\hline Years practicing audiology & $17(10.66)$ & \\
\hline $\begin{array}{l}\text { Years supervising graduate } \\
\text { students }\end{array}$ & $11(8.57)$ & \\
\hline 1 to 5 years & & $28(58)$ \\
\hline 6 to 10 years & & $29(59)$ \\
\hline 11 years or more & & $43(88)$ \\
\hline Age & $43(10.71)$ & \\
\hline Prefer not to answer & & $4(8)$ \\
\hline \multicolumn{3}{|l|}{ Gender } \\
\hline Female & & $88(174)$ \\
\hline Male & & $11(22)$ \\
\hline Prefer not to answer & & $1(2)$ \\
\hline $\begin{array}{l}\text { Percent time spent } \\
\text { supervising }\end{array}$ & $56(24.74)$ & \\
\hline \multicolumn{3}{|l|}{ Race } \\
\hline White & & $91(184)$ \\
\hline Other & & $7(13)$ \\
\hline Prefer not to answer & & $2(5)$ \\
\hline \multicolumn{3}{|l|}{ Ethnicity } \\
\hline Not Hispanic or Latino & & $96(179)$ \\
\hline Hispanic or Latino & & $2(4)$ \\
\hline Prefer not to answer & & $2(4)$ \\
\hline
\end{tabular}

the supervisory relationship (three items); (c) confidence related to teaching counseling skills (ten items); (d) frequency of strategies used to provide feedback to students (five items); and (e) self-efficacy related to teaching counseling (11 items). There were two open-ended questions to explore challenges mentoring graduate students in their development of counseling skills, and additional comments related to successes and challenges experienced. Supervisors reported their perceptions on fivepoint Likert scales (importance $[1=$ not important to $5=$ extremely important]; confidence $[1=$ not confident to $5=$ extremely confident]; frequency of student feedback [ $1=$ not addressed to $5=>75 \%$ ]; self-efficacy in supporting student learning $[1=$ not confident to $5=\mathrm{ex}-$ tremely confident]).

\section{Analysis}

Descriptive data analysis was completed using SPSS (v23), including measures of central tendency to identify variance in practices and mentoring gaps. Three domains were included in the survey (i.e., importance, teaching confidence, and self-efficacy in supporting student learning). Item analyses of the domains revealed good to excellent internal consistency for each scale: importance $(\mathrm{n}=203$; items $=13$; Cronbach's $\alpha=0.83)$, teaching confidence $(\mathrm{n}=203$; items $=10$; Cronbach's $\alpha=0.87$ ), and self-efficacy in supporting student learning $(\mathrm{n}=198$; items $=11$; Cronbach's $\alpha=0.93)$. To explore differences in each domain based on supervision 
experience, participants were grouped based on years of supervisory experience (i.e., 1 to 5 years; 6 to 10 years, 11 or more years). Differences among groups for each domain were explored using analysis of variance and post hoc analysis using Tukey's honest significant difference. Supervisors provided written feedback in response to two open questions about the challenges and successes they experience supervising students for development of counseling skills; reported in a separate article.

\section{RESULTS}

$\mathrm{P}$ articipants were asked whether their graduate training program included a required counseling course for their audiology students, and if so, the year the course is offered. Most participants reported their program requires a counseling course $88 \%(\mathrm{n}=176)$, and of those, $15 \%(\mathrm{n}=29)$ are during the first year, $43 \%(\mathrm{n}=85)$ during the second year, and 20\% $(\mathrm{n}=$ 40) during the third year. Some participants $(9 \% ; n=$ 18) reported alternative approaches, including offering the course every other year, including counseling with other content or offering the course pending enrollment, and $12 \%(\mathrm{n}=25)$ reported their program does not require a counseling course.

\section{Importance}

Participants rated how important they feel it is to teach audiology graduate students ten skills related to counseling with clients, and they also rated importance of three skills related to the supervisory relationship with students. For ease in observing trends, responses were combined for "not important and slightly important," and for "very important and extremely important" (see Table 2). For all ten counseling skill items, most of the supervisors $(63 \%$ to $100 \% ; n=130-205)$ rated the items as very or extremely important. Almost all of the supervisors $(96 \% ; n=196)$ reported it is very or extremely important to build rapport with the student during supervision. Fewer supervisors reported it is very or extremely important to examine implications of gender similarities/differences between supervisor and student ( $31 \% ; \mathrm{n}=64)$ and examine implications of culture/ ethnicity similarities/differences between supervisor and student $(50 \% ; \mathrm{n}=102)$.

\section{Confidence in Teaching Skills}

Participants rated how confident they feel teaching audiology graduate students ten counseling skills. For ease in observing trends, responses were combined for "not confident and slightly confident," and for "very confident and extremely confident" (see Table 3 ). Threequarters or more of the participants $(77-97 \%$; $n=158$ 200) reported feeling very or extremely confident in seven of the ten skills. There was a split in the data with fewer participants feeling confident in teaching students to talk with clients about their (the clients') strong emotions when receiving difficult news $(65 \% ; n=133)$, interest in talking to others with similar experiences $(66 \% ; \mathrm{n}=136)$, and internal challenges (e.g., depression, stress, and anxiety) (53\%; $\mathrm{n}=109)$.

To explore supervisory teaching methods for counseling skill acquisition, supervisors rated how often they use each of five items. For ease in observing trends, responses were combined for "I do not address this and $1-25 \%$." More than $75 \%$ of the time was reported by some supervisors for discussing counseling skill

Table 2. Importance of Teaching Skills and Supervisory Relationship with Students

\begin{tabular}{|c|c|c|c|}
\hline \multirow[b]{2}{*}{ How Important Is It to Teach Students to Talk to Clients about... } & \multicolumn{3}{|c|}{ Percent $(n)$} \\
\hline & $\begin{array}{l}\text { Not to Slightly } \\
\text { Important }\end{array}$ & $\begin{array}{l}\text { Moderately } \\
\text { Important }\end{array}$ & $\begin{array}{l}\text { Very to Extremely } \\
\text { Important }\end{array}$ \\
\hline Their expectations (e.g., outcomes, process) & 0 & 0 & $100(205)$ \\
\hline Learning new skills (e.g., checking hearing aid function) & 0 & $7(15)$ & $93(190)$ \\
\hline Their strong emotions when receiving difficult news (e.g., crying) & $3(5)$ & $5(11)$ & $92(188)$ \\
\hline Overcoming barriers with daily management & $1(1)$ & $10(21)$ & $89(182)$ \\
\hline Their perceptions about hearing loss & 0 & $11(22)$ & $89(183)$ \\
\hline Their network of support (e.g., spouse, family, friend) & $1(1)$ & $12(25)$ & $87(179)$ \\
\hline Their internal challenges (e.g., depression, stress, anxiety) & $2(4)$ & $18(37)$ & $80(164)$ \\
\hline Their external challenges (e.g., lack of knowledge) & $4(8)$ & $19(39)$ & $77(157)$ \\
\hline Technical information (e.g., hearing aid components) & $8(16)$ & $24(50)$ & $68(139)$ \\
\hline Their interest in talking to others with similar experiences & $6(16)$ & $31(64)$ & $63(130)$ \\
\hline \multicolumn{4}{|l|}{ As a Supervisor, How Important Is It for You to... } \\
\hline Build rapport with the student during supervision & 0 & $4(9)$ & $96(196)$ \\
\hline $\begin{array}{l}\text { Examine implications of culture/ethnicity similarities/differences between } \\
\text { supervisor and student }\end{array}$ & $14(30)$ & $36(73)$ & $50(102)$ \\
\hline $\begin{array}{l}\text { Examine implications of gender similarities/differences between supervisor and } \\
\text { student }\end{array}$ & $33(68)$ & $36(73)$ & $31(64)$ \\
\hline
\end{tabular}




\begin{tabular}{|c|c|c|c|}
\hline \multirow[b]{2}{*}{$\begin{array}{l}\text { How Confident Do You Feel in Your Ability to Teach Students to Talk with Clients } \\
\text { about... }\end{array}$} & \multicolumn{3}{|c|}{ Percent (n) } \\
\hline & $\begin{array}{l}\text { Not to Slightly } \\
\text { Confident }\end{array}$ & $\begin{array}{l}\text { Moderately } \\
\text { Confident }\end{array}$ & $\begin{array}{c}\text { Very to } \\
\text { Extremely } \\
\text { Confident }\end{array}$ \\
\hline Learning new skills (e.g., checking hearing aid function) & $1(1)$ & $2(4)$ & $97(200)$ \\
\hline Their expectations (e.g., outcomes, process) & 0 & $6(13)$ & $94(192)$ \\
\hline Technical information (e.g., hearing aid components) & $1(3)$ & $6(12)$ & $93(190)$ \\
\hline Their perceptions about hearing loss & $2(4)$ & $12(24)$ & $86(177)$ \\
\hline Overcoming barriers with daily management & $1(2)$ & $15(30)$ & $84(172)$ \\
\hline Their network of support (e.g., spouse, family, friend) & $1(2)$ & $22(44)$ & $77(159)$ \\
\hline Their external challenges (e.g., lack of knowledge) & $3(6)$ & $20(40)$ & $77(158)$ \\
\hline Their strong emotions when receiving difficult news (e.g., crying) & $5(10)$ & $30(62)$ & $65(133)$ \\
\hline Their interest in talking to others with similar experiences & $5(10)$ & $29(59)$ & $66(136)$ \\
\hline Their internal challenges (e.g., depression, stress, anxiety) & $14(28)$ & $33(68)$ & $53(109)$ \\
\hline
\end{tabular}

performance with students after the appointment (52\%; $\mathrm{n}=106$ ); discussing counseling skills with students before the appointment $(29 \% ; \mathrm{n}=60)$; using a rubric to evaluate student competencies for specific counseling skills (29\%; $\mathrm{n}=58$ ); providing written feedback to students about their counseling skill performance after the appointment $(22 \% ; \mathrm{n}=45)$; and using a performance feedback form specific to counseling skill development $(15 \% ; \mathrm{n}=30)$. A few supervisors provided comments indicating they provide feedback about counseling at midsemester and/or end of the semester, and they include counseling within a comprehensive rubric that includes skills other than counseling.

\section{Self-Efficacy in Supporting Student Learning}

Participants reported how confidently they felt they could effectively "right now" provide supervisory support for student counseling development for 11 items. For ease in observing trends, responses were combined for "not confident and slightly confident," and for "very confident and extremely confident" (see Table 4). Many felt very or extremely confident in seven of the 11 items $(61-82 \% ; \mathrm{n}=125-169)$. For four of the items, fewer felt as confident: explore student's feelings concerning a specific counseling technique and/or intervention $(51 \% ; \mathrm{n}=104)$; facilitate student's self-exploration of confidence and/or worries related to counseling (50\%; $\mathrm{n}=102$ ); provide alternative interventions and/or conceptualizations for the student to use $(49 \% ; \mathrm{n}=99)$; and explain the rationale behind specific counseling strategies $(47 \% ; \mathrm{n}=97)$.

\section{Supervisory Experience}

The influence of number of years supervising (i.e., 1 to 5 years; 6 to 10 years; 11 or more years) was explored for each of the domains. Analysis of variance showed no statistically significant effect for the importance domain $F_{(2,202)}=0.807, p=0.448$. There was a main effect of years

Table 4. Self-Efficacy in Supporting Student Learning in Counseling

\begin{tabular}{|c|c|c|c|}
\hline \multirow[b]{2}{*}{ Right Now, I Feel I Can Effectively... } & \multicolumn{3}{|c|}{ Percent (n) } \\
\hline & $\begin{array}{c}\text { Not to } \\
\text { Somewhat } \\
\text { Confident }\end{array}$ & $\begin{array}{c}\text { Moderately } \\
\text { Confident }\end{array}$ & $\begin{array}{l}\text { Very to } \\
\text { Extremely } \\
\text { Confident }\end{array}$ \\
\hline Encourage student's discussion of client problems, motivation, etc. & $5(9)$ & $13(27)$ & $82(169)$ \\
\hline Teach/model counseling intervention techniques & $5(11)$ & $19(38)$ & $76(156)$ \\
\hline Evaluate counseling interactions between students and clients & $4(8)$ & $21(42)$ & $75(155)$ \\
\hline Help students define personal competencies and areas for growth & $8(16)$ & $22(44)$ & $70(145)$ \\
\hline Identify appropriate counseling interventions to promote positive client change & $9(19)$ & $25(50)$ & $66(135)$ \\
\hline Solicit and address the professional needs of the student during the session & $9(19)$ & $26(52)$ & $65(130)$ \\
\hline Encourage student's brainstorming of strategies and/or interventions & $11(23)$ & $28(57)$ & $61(125)$ \\
\hline $\begin{array}{l}\text { Explore student's feelings concerning a specific counseling technique and/or } \\
\text { intervention }\end{array}$ & $15(31)$ & $34(70)$ & $51(104)$ \\
\hline Facilitate student's self-exploration of confidence and/or worries related to counseling & $14(30)$ & $36(73)$ & $50(102)$ \\
\hline Provide alternative interventions and/or conceptualizations for the student to use & $20(42)$ & $31(63)$ & $49(99)$ \\
\hline Explain the rationale behind specific counseling strategies & $25(51)$ & $28(56)$ & $47(97)$ \\
\hline
\end{tabular}


Table 5. Effect of Years of Supervision Experience on Confidence

\begin{tabular}{|c|c|c|c|c|c|}
\hline & $\mathrm{N}$ & $\mathrm{M}(\mathrm{SD})$ & $\mathrm{Cl}$ & $p$ & Cohen's d \\
\hline \multicolumn{6}{|l|}{ Confidence in teaching } \\
\hline Group 1: 1 to 5 years & 58 & $3.96(0.45)$ & $3.84-4.08$ & & \\
\hline Group 2: 6 to 10 years & 59 & $4.06(0.51)$ & $3.93-4.19$ & & \\
\hline Group 3: 11 or more years & 88 & $4.26(0.51)$ & $4.15-4.37$ & & \\
\hline Groups 1 and 3 & & & & $0.001^{*}$ & 0.62 \\
\hline Groups 2 and 3 & & & & $0.047^{*}$ & 0.39 \\
\hline \multicolumn{6}{|c|}{ Confidence in supervisory support } \\
\hline Group 1: 1 to 5 years & 58 & $3.54(0.56)$ & $3.40-3.69$ & & \\
\hline Group 2: 6 to 10 years & 59 & $3.68(0.84)$ & $3.46-3.90$ & & \\
\hline Group 3: 11 or more years & 88 & $3.86(0.78)$ & $3.70-4.03$ & & \\
\hline Groups 1 and 3 & & & & $0.031^{*}$ & 0.47 \\
\hline
\end{tabular}

${ }^{*}$ Statistical significance at $p<0.05$.

$\mathrm{Cl}=$ confidence interval; $\mathrm{SD}=$ standard deviation.

of supervisory experience on confidence in teaching counseling skills, $F_{(2,202)}=6.92, p=0.001$, and self-efficacy in supporting student learning $F_{(2,202)}=3.37, p=0.036$. Supervisors with more experience reported higher levels of confidence for teaching counseling skills and in providing supervisory support for counseling skill development. Effect size analyses using Cohen's $d$ indicated small to medium differences between the means (see Table 5).

\section{DISCUSSION}

$\mathrm{P}$ artnering with patients within the context of a therapeutic relationship is essential in audiology service delivery and can be a key component in helping patients achieve desired outcomes. To be effective, counseling conversations need to assess and address the range of challenges patients are experiencing that interfere with the intervention process, through intentional and targeted interactions. Teaching counseling in audiology graduate programs provides the foundation for effective practices. This study used a self-report measure to explore perspectives and practices of supervisors in audiology graduate training programs related to mentoring students in the acquisition of counseling skills. This study used a self-report measure; therefore, differences between supervisors' perceptions and actual practices are not known. In addition, supervisors were not asked to report on counseling training they received; therefore, their knowledge and skill level related to counseling and how it may influence their teaching is not known.

The importance of counseling education in audiology graduate programs was broadly supported by audiology supervisors in this study. Audiologists in other studies have also indicated the importance of counseling within their practice (Meibos et al, 2016; 2017). Most of the supervisors in this study reported students take a required course in counseling during their graduate training program, only $12 \%$ indicated their program did not require a counseling course. This represents an increase compared with reports of required counseling courses before the transition from a masters to an $\mathrm{AuD}$ degree in audiology (McCarthy et al, 1986). Even though more programs now require a counseling course, a recent syllabi review of counseling courses in audiology programs revealed variability in content areas covered within the courses (Whicker et al, 2017). In this study supervisors also reported a wide range of variability in how often and in what ways they use teaching strategies (i.e., discussion about counseling before or after sessions, written feedback, and performance feedback) with students related to counseling skill acquisition and evaluation of performance.

Even with this variability, supervisors generally reported a high level of confidence in teaching counseling skills to students; although, they were less confident in teaching students how to address patients' internal challenges, strong emotions, and interest in talking to other patients with similar experiences. Self-efficacy varied among supervisors in supporting student learning in counseling. Self-efficacy was lower for explaining rationales behind specific counseling strategies, providing alternative interventions or ways for students to conceptualize counseling and in helping students to explore their own confidence and/or worries related to counseling. Variability in self-efficacy may be related to counseling training or lack of training, the clinical supervisors have received, and may limit their ability to effectively support student learning. Experience being a supervisor; however, had a statistically significant influence on teaching confidence and self-efficacy in supporting student learning. Supervisors with more years of experience reported higher levels of teaching confidence and self-efficacy, providing evidence for the importance of providing training and support for supervisors related to the supervisory process (ASHA, 2017).

\section{Supervisory Relationship}

The supervisory relationship influences learning. Elements within the supervisory relationship can influence 
whether a student feels safe sharing their concerns and challenges, revealing underlying barriers to learning, particularly as it relates to their communication patterns with patients. To support counseling skill development, supervisors must attend to the relationship they cultivate with their students. Almost all of the supervisors in this study (96\%) indicated building a rapport with students during supervision is very or extremely important. Fewer supervisors recognized the importance of examining the implications of similarities/differences between the supervisor and supervisee related to culture/ethnicity $(50 \%)$ and gender $(31 \%)$. Perceptions placing less importance on differences between the supervisor and supervisee for gender and culture/ethnicity may be related to the demographic composition of audiologists in the United States; only 15\% are male and only $8 \%$ are members of a racial minority (ASHA, 2016). The underrepresentation of diversity within the profession is a reason to place higher importance and recognition of the influence within the supervisory process and within clinical service provision. Students need explicit awareness of gender and culture/ethnicity differences between themselves and patient groups.

\section{Gender}

Although the findings on the impact of gender within the supervisory relationship are mixed (Bernard and Goodyear, 2014), supervisors must remain aware of their own gender attitudes and be willing to initiate conversations regarding gender within the supervisory relationship (Rarick and Ladany, 2013). Gender-related conversations lead to higher levels of satisfaction with supervision and the supervisory working alliance (Walker et al, 2007). Some common scenarios involving gender differences may include a female supervisor thinking a male supervisee is not taking her seriously (Bernard and Goodyear, 2014), or a female supervisee deferring power to a supervisor or others in the training environment (Rarick and Ladany, 2013). Similarly, evidence has suggested male supervisees are asked for their opinion, whereas female supervisees are told what to do (Granello et al, 1997; Granello, 2003). These examples are indicative of approaches to gender-related events perpetuating cultural stigmas. If messages sent within the supervisory process do not support and empower supervisees, supervisees are "less likely to learn the skills and techniques that are essential when working with clients" (Walker et al, 2007, p. 17).

\section{Race/Ethnicity}

"The prerequisite for cultural competence has always been racial self-awareness" (Sue et al, 2007, p. 283). Clinical supervisors have a responsibility to address issues of multicultural competence within the supervisory relationship, but with racial/ethnic differences, the supervisee might encounter in the direct provision of services to clients. Failure to address the issue of multicultural competence has been suggested as one component of ineffective supervision (Ladany, 2014), and when supervisors fail to initiate a discussion on multiculturalism, international students in counseling training programs have ended up "silencing themselves" in supervision (Sangganjanavanich and Black, 2009). Silencing here represents a feeling on the part of the students that their opinions and values are not heard, leading to a reluctance to discuss issues or concerns and otherwise engage in the supervisory process. Supervisors who engage in multicultural discussion with their supervisees enhance the supervisory working alliance; conversely, when supervisors chose not to engage in multicultural discussions supervisees reported having a lower level of satisfaction with the supervisory working alliance (Ng and Smith, 2012).

\section{Future Research}

Further research is needed to better understand factors that facilitate/impede supervisors' ability to consistently and effectively teach counseling skills. For example, findings from the following research questions would provide critical insights:

- What are current models used for teaching counseling in audiology?

- How effective are current models used in AuD graduate training, for counseling courses and supervision, in facilitating implementation of skills in practice?

- What training and support do supervisors need to effectively teach counseling skills to AuD students?

- What teaching strategies are needed in supervision of $\mathrm{AuD}$ students to increase use of counseling skills, and how long is supervision needed before skills are maintained in practice?

- What are supervisors' attitudes about their role in counseling, and does attitude influence supervision practices in audiology?

Audiology graduate program attention to addressing counseling training gaps can offer benefits to upcoming audiologists, and their future patients. Clearer guidance for counseling education from audiology accrediting bodies could also support more systematic training implementation.

\section{CONCLUSION}

Q upervision of audiology graduate students is an im$\$$ portant component for supporting counseling skill 
development. This study found audiology supervisors in $\mathrm{AuD}$ programs believe counseling is important to teach to students; however, they report variability in use of methods to provide feedback to students about their counseling skills and report variable self-efficacy for supporting student learning. Future audiologists would benefit from a more systematic approach to graduate training for counseling skill development.

\section{REFERENCES}

American Academy of Audiology (AAA). (2004) Scope of Practice. http://www.audiology.org/publications-resources/document-library/ scope-practice. Accessed October 30, 2017.

American Academy of Audiology (AAA). (2013) Clinical Practice Guidelines. Pediatric Amplification Protocol. http://galster.net/wpcontent/uploads/2013/07/AAA-2013-Pediatric-Amp-Guidelines.pdf. Accessed October 30, 2017.

American Speech-Language-Hearing Association (ASHA). (2004) Scope of practice in audiology [Scope of Practice]. www.asha.org/ policy. Accessed October 31, 2017.

American Speech-Language-Hearing Association (ASHA). (2006) Preferred practice patterns for the profession of audiology [Preferred Practice Patterns]. www.asha.org/policy. Accessed October 31,2017

American Speech-Language-Hearing Association (ASHA). (2008) Guidelines for audiologists providing informational and adjustment counseling to families of infants and young children with hearing loss birth to 5 years of age [Guidelines]. www.asha.org/ policy. Accessed October 31, 2017.

American Speech-Language-Hearing Association (ASHA). (2013) Ad Hoc Committee on Supervision. http://www.asha.org/uploadedFiles/ Report-Ad-Hoc-Committee-on-Supervision.pdf. Accessed October 31, 2017.

American Speech-Language-Hearing Association (ASHA). (2016) Highlights and Trends: Member and Affiliate Counts, Year-End 2016. http://www.asha.org/uploadedFiles/2016-Member-Counts. pdf. Accessed October 31, 2017.

American Speech-Language-Hearing Association (ASHA). (2017) Clinical Education and Supervision. http://www.asha.org/PracticePortal/Professional-Issues/Clinical-Education-and-Supervision/. Accessed October 31, 2017.

Ammentorp J, Sabroe S, Kofoed PE, Mainz J. (2007) The effect of training in communication skills on medical doctors' and nurses' self-efficacy. A randomized controlled trial. Patient Educ Couns 66(3):270-277.

Ancis J, Ladany N. (2010) A multicultural framework for counselor supervision: Knowledge and skills. In: Ladany N, Bradley L, eds. Counselor Supervision. 4th ed. New York, NY: Routledge.

Bernard JM, Goodyear RK. (2014) Fundamentals of Clinical Supervision. 5th ed. Boston, MA: Pearson Publishing.

Clark J, English K. (2014) Counseling-Infused Audiologic Care. Boston, MA: Allyn \& Bacon.

Delvaux N, Razavi D, Marchal S, Brédart A, Farvacques C, Slachmuylder JL. (2004) Effects of a 105 hours psychological training program on attitudes, communication skills and occupational stress in oncology: a randomised study. $\mathrm{Br} J$ Cancer 90(1): 106-114.
Ekberg K, Grenness C, Hickson L. (2014) Addressing patients' psychosocial concerns regarding hearing aids within audiology appointments for older adults. Am J Audiol 23(3): $337-350$.

Flasher L, Fogle P. (2012) Counseling Skills for Speech-Language Pathologists and Audiologists. Clifton Park, NY: Delmar-Cengage Learning.

Granello DH. (2003) Influence strategies in the supervisory dyad: an investigation into the effects of gender and age. Couns Educ Superv 41:279-293.

Granello DH, Beamish PM, Davis TE. (1997) Supervisee empowerment: does gender make a difference? Couns Educ Superv 36: 305-317.

Grenness C, Hickson L, Laplante-Lévesque A, Meyer C, Davidson B. (2015) The nature of communication throughout diagnosis and management planning in initial audiologic rehabilitation consultations. J Am Acad Audiol 26(1):36-50. http://10.0. 14.182/jaaa.26.1.5

Heaven C, Clegg J, Maguire P. (2006) Transfer of communication skills training from workshop to workplace: the impact of clinical supervision. Patient Educ Couns 60(3):313-325.

Heritage J, Maynard DW. (2006) Problems and prospects in the study of physician-patient interactions: 30 years of research. Annu Rev Sociol 32:351-374.

Ladany N. (2014) The ingredients of supervisor failure. J Clin Psychol 70(11):1094-1103.

Ladany N, Mori Y, Mehr KE. (2013) Effective and ineffective supervision. Couns Psychol 41(1):28-47.

Levinson W, Lesser CS, Epstein RM. (2010) Developing physician communication skills for patient-centered care. Health Aff (Millwood) 29(7):1310-1318.

Luterman D. (2008) Counseling Persons with Communication Disorders and their Families. Austin, TX: Pro-ed.

McCarthy P, Culpepper NB, Lucks L. (1986) Variability in counseling experiences and training among ESB-accredited programs. ASHA 28(9):49-52.

Meibos A, Muñoz K, Schultz J, Price T, Whicker JJ, Caballero A, Graham L. (2017) Counselling users of hearing technology: a comprehensive literature review. Int J Audiol 1-7.

Meibos A, Muñoz K, White K, Preston E, Pitt C, Twohig M. (2016) Audiologist practices: parent hearing aid education and support. J Am Acad Audiol 27(4):324-332. http://10.0.14.182/jaaa.15007.

Muñoz K, Ong C, Borrie S, Nelson LH, Twohig M. (2017) Audiologists' communication behavior during hearing device management appointments. Int J Audiol 56(5):328-336.

Nair EL, Cienkowski KM. (2010) The impact of health literacy on patient understanding of counseling and education materials. Int J Audiol 49(2):71-75.

Ng KM, Smith SD. (2012) Training level, acculturation, role ambiguity, and multicultural discussions in training and supervising international counseling students in the United States. Int $J$ Adv Counselling 34(1):72-86.

Rarick SL, Ladany N. (2013) The relationship of supervisor and trainee gender match and gender attitude match to supervisory style and the supervisory working alliance. Couns Psychother Res 13(2):138-144. 
Robinson JH, Callister LC, Berry JA, Dearing KA. (2008) Patient-centered care and adherence: definitions and applications to improve outcomes. J Am Acad Nurse Pract 20(12): $600-607$.

Ross M. (2004) The audiogram: explanation and significance. Hear Loss 25:29-33.

Sangganjanavanich VF, Black LL. (2009) Clinical supervision for international counselors-in-training: implications for supervisors. J Prof Couns Pract Theory Res 37(2):52-65.

Schultz JC, Ososkie JN, Fried JH, Nelson RE, Bardos AN. (2002) Clinical supervision in public rehabilitation counseling settings. Rehabil Couns Bull 45(4):213-222.

Shames GH. (2006) Counseling the Communicatively Disabled and their Families: A Manual for Clinicians. Mahwah, NJ: Lawrence Erlbaum Associates, Inc.

Sue DW, Capodilupo CM, Torino GC, Bucceri JM, Holder AM, Nadal KL, Esquilin M. (2007) Racial microaggressions in everyday life: implications for clinical practice. Am Psychol 62(4):271-286.

Walker JA, Ladany N, Pate-Carolan LM. (2007) Gender-related events in psychotherapy supervision: female trainee perspectives. Couns Psychother Res 7(1):12-18.

Watermeyer J, Kanji A, Cohen A. (2012) Caregiver recall and understanding of pediatric diagnostic information and assessment feedback. Int J Audiol 51(12):864-869.

Whicker J, Muñoz K, Butcher G, Schultz J, Twohig M. (2017) Counseling training in AuD programs: a syllabi review. Hear $J$ 70(8):36-39.

World Health Organization (WHO). (2015) Deafness and Hearing Loss Fact Sheet http://www.who.int/mediacentre/factsheets/ fs300/en/. Accessed October 31, 2017.

Zolnierek KB, Dimatteo MR. (2009) Physician communication and patient adherence to treatment: a meta-analysis. Med Care 47(8): 826-834. 


\section{APPENDIX}

\section{Student Counseling Skill Development in AuD Programs: Audiology Supervisors' Perceptions and} Practices

1. Years practicing audiology: 2. Years supervising audiology graduate students:

3. Your age: $\square$ Prefer not to answer 4. Gender: $\square \mathrm{M} \square \mathrm{F} \square$ Prefer not to answer

5. Approximate percent of your time spent supervising audiology graduate students:

6. Race: $\square$ American Indian or Alaska Native $\square$ Asian $\square$ Black or African America

$\square$ Native Hawaiian or Other Pacific Islander $\square$ White $\square$ Other:

Prefer not to answer

7. Ethnicity: $\square$ Hispanic or Latino $\square$ Not Hispanic or Latino $\square$ Prefer not to answer

8. Students take a required counseling course: __ No __ Yes, during__ Year $1 \_$Year $2 \_$Year 3

\section{TEACHING COUNSELING}

9. Indicate how important you feel it is to teach each of the following skills to students:

\begin{tabular}{|c|c|c|c|c|c|}
\hline How Important Is It to Teach Students to Talk to Clients about... & $\begin{array}{l}\text { Not } \\
\text { Important }\end{array}$ & $\begin{array}{l}\text { Slightly } \\
\text { Important }\end{array}$ & $\begin{array}{l}\text { Moderately } \\
\text { Important }\end{array}$ & $\begin{array}{c}\text { Very } \\
\text { Important }\end{array}$ & $\begin{array}{l}\text { Extremely } \\
\text { Important }\end{array}$ \\
\hline a. Their strong emotions when receiving difficult news (e.g., crying) & 1 & 2 & 3 & 4 & 5 \\
\hline b. Technical information (e.g., hearing aid components) & 1 & 2 & 3 & 4 & 5 \\
\hline c. Learning new skills (e.g., checking hearing aid function) & 1 & 2 & 3 & 4 & 5 \\
\hline d. Overcoming barriers with daily management & 1 & 2 & 3 & 4 & 5 \\
\hline e. Their perceptions about hearing loss & 1 & 2 & 3 & 4 & 5 \\
\hline f. Their expectations (e.g., outcomes, process) & 1 & 2 & 3 & 4 & 5 \\
\hline g. Their network of support (e.g., spouse, family, friend) & 1 & 2 & 3 & 4 & 5 \\
\hline h. Their internal challenges (e.g., depression, stress, anxiety) & 1 & 2 & 3 & 4 & 5 \\
\hline i. Their interest in talking to others with similar experiences & 1 & 2 & 3 & 4 & 5 \\
\hline j. Their external challenges (e.g., lack of knowledge) & 1 & 2 & 3 & 4 & 5 \\
\hline \multicolumn{6}{|l|}{ As a Supervisor, How Important Is It for You to: } \\
\hline k. Build rapport with the student during supervision & 1 & 2 & 3 & 4 & 5 \\
\hline $\begin{array}{l}\text { I. Examine implications of gender similarities/differences between } \\
\text { supervisor and student }\end{array}$ & 1 & 2 & 3 & 4 & 5 \\
\hline $\begin{array}{l}\text { m. Examine implications of culture/ethnicity similarities/differences } \\
\text { between supervisor and student }\end{array}$ & 1 & 2 & 3 & 4 & 5 \\
\hline
\end{tabular}

10. Indicate how confident you feel in your ability to teach each of the following skills to students:

\begin{tabular}{|c|c|c|c|c|c|}
\hline $\begin{array}{l}\text { How Confident Do you Feel in Your Ability to Teach Students to } \\
\text { Talk with Clients about: }\end{array}$ & $\begin{array}{c}\text { Not } \\
\text { Confident }\end{array}$ & $\begin{array}{l}\text { Slightly } \\
\text { Confident }\end{array}$ & $\begin{array}{l}\text { Moderately } \\
\text { Confident }\end{array}$ & $\begin{array}{c}\text { Very } \\
\text { Confident }\end{array}$ & $\begin{array}{l}\text { Extremely } \\
\text { Confident }\end{array}$ \\
\hline a. Their strong emotions when receiving difficult news (e.g., crying) & 1 & 2 & 3 & 4 & 5 \\
\hline b. Technical information (e.g., hearing aid components) & 1 & 2 & 3 & 4 & 5 \\
\hline c. Learning new skills (e.g., checking hearing aid function) & 1 & 2 & 3 & 4 & 5 \\
\hline d. Overcoming barriers with daily management & 1 & 2 & 3 & 4 & 5 \\
\hline e. Their perceptions about hearing loss & 1 & 2 & 3 & 4 & 5 \\
\hline f. Their expectations (e.g., outcomes, process) & 1 & 2 & 3 & 4 & 5 \\
\hline g. Their network of support (e.g., spouse, family, friend) & 1 & 2 & 3 & 4 & 5 \\
\hline h. Their internal challenges (e.g., depression, stress, anxiety) & 1 & 2 & 3 & 4 & 5 \\
\hline i. Their interest in talking to others with similar experiences & 1 & 2 & 3 & 4 & 5 \\
\hline j. Their external challenges (e.g., lack of knowledge) & 1 & 2 & 3 & 4 & 5 \\
\hline
\end{tabular}


11. What challenges do you experience in mentoring graduate students in their development of counseling skills?

12. Indicate how often you use each of the following to teach students skills specific to counseling:

\begin{tabular}{|c|c|c|c|c|c|}
\hline & $\begin{array}{c}\text { I Do not Address } \\
\text { this }\end{array}$ & $\begin{array}{c}1- \\
25 \%\end{array}$ & $\begin{array}{l}26- \\
50 \%\end{array}$ & $\begin{array}{l}51- \\
75 \%\end{array}$ & $>75 \%$ \\
\hline a. Discuss counseling skills with students before the appointment & 1 & 2 & 3 & 4 & 5 \\
\hline b. Discuss counseling skill performance with students after the appointment & 1 & 2 & 3 & 4 & 5 \\
\hline $\begin{array}{l}\text { c. Provide written feedback to students about their counseling skill performance after the } \\
\text { appointment }\end{array}$ & 1 & 2 & 3 & 4 & 5 \\
\hline d. Use a performance feedback form specific to counseling skill development & 1 & 2 & 3 & 4 & 5 \\
\hline e. Use a rubric to evaluate student competencies for specific counseling skills & 1 & 2 & 3 & 4 & 5 \\
\hline
\end{tabular}

13. Indicate how confident you feel in your ability to address each of the following within supervision:

\begin{tabular}{|c|c|c|c|c|c|}
\hline Right Now, I Feel I Can Effectively: & $\begin{array}{c}\text { Not } \\
\text { Confident }\end{array}$ & $\begin{array}{l}\text { Somewhat } \\
\text { Confident }\end{array}$ & $\begin{array}{l}\text { Moderately } \\
\text { Confident }\end{array}$ & $\begin{array}{c}\text { Very } \\
\text { Confident }\end{array}$ & $\begin{array}{l}\text { Extremely } \\
\text { Confident }\end{array}$ \\
\hline a. Evaluate counseling interactions between students and clients & 1 & 2 & 3 & 4 & 5 \\
\hline $\begin{array}{l}\text { b. Identify appropriate counseling interventions to promote positive } \\
\text { client change }\end{array}$ & 1 & 2 & 3 & 4 & 5 \\
\hline c. Teach/model counseling intervention techniques & 1 & 2 & 3 & 4 & 5 \\
\hline d. Explain the rationale behind specific counseling strategies & 1 & 2 & 3 & 4 & 5 \\
\hline $\begin{array}{l}\text { e. Provide alternative interventions and/or conceptualizations for the } \\
\text { student to use }\end{array}$ & 1 & 2 & 3 & 4 & 5 \\
\hline $\begin{array}{l}\text { f. Encourage student's brainstorming of strategies and/or } \\
\text { interventions }\end{array}$ & 1 & 2 & 3 & 4 & 5 \\
\hline $\begin{array}{l}\text { g. Encourage student's discussion of client problems, motivation, } \\
\text { etc. }\end{array}$ & 1 & 2 & 3 & 4 & 5 \\
\hline $\begin{array}{l}\text { h. Solicit and address the professional needs of the student during } \\
\text { the session }\end{array}$ & 1 & 2 & 3 & 4 & 5 \\
\hline $\begin{array}{l}\text { i. Explore student's feelings concerning a specific counseling } \\
\text { technique and/or intervention }\end{array}$ & 1 & 2 & 3 & 4 & 5 \\
\hline $\begin{array}{l}\text { j. Facilitate student's self-exploration of confidence and/or worries } \\
\text { related to counseling }\end{array}$ & 1 & 2 & 3 & 4 & 5 \\
\hline k. Help students define personal competencies and areas for growth & 1 & 2 & 3 & 4 & 5 \\
\hline
\end{tabular}

14. Please provide any additional comments that you feel would help us understand challenges and successes you have experienced related to counseling in your practice and in teaching counseling to students:

Thank you for your time! 